\title{
Serum Cytokine Signature That Discriminates Helicobacter pylori Positive and Negative Juvenile Gastroduodenitis
}

\author{
Svetlana F. Khaiboullina ${ }^{1}$, Sayar Abdulkhakov ${ }^{1,2}$, Alsu Khalikova ${ }^{2}$, Dilyara Safina ${ }^{1}$, \\ Ekaterina V. Martynova', Yuriy Davidyuk ${ }^{1}$, Felix Khuzin ${ }^{2}$, Rezeda Faizullina ${ }^{2}$, \\ Vincent C. Lombardi ${ }^{1,3}$, Georgi V. Cherepnev ${ }^{1,4}$ and Albert A. Rizvanov ${ }^{1 *}$ \\ ${ }^{1}$ Institute of Fundamental Medicine and Biology, Kazan Federal University, Kazan, Russia, ${ }^{2}$ Kazan State Medical University, \\ Kazan, Russia, ${ }^{3}$ Nevada Center for Biomedical Research, Reno, NV, USA, ${ }^{4}$ Department of Clinical Laboratory Diagnostics, \\ Kazan State Medical Academy, Kazan, Russia
}

OPEN ACCESS

Edited by:

Ryo Inoue,

Kyoto Prefectural University, Japan

Reviewed by:

M. Victoria Delpino,

National Scientific and Technical

Research Council (CONICET),

Argentina

Gustavo Adolfo Romero-Perez,

Kyoto Institute of Nutrition and

Pathology, Japan

${ }^{*}$ Correspondence:

Albert A. Rizvanov

albert.rizvanov@kpfu.ru

Specialty section: This article was submitted to

Microbial Immunology, a section of the journal

Frontiers in Microbiology

Received: 10 September 2015 Accepted: 15 November 2016

Published: 15 December 2016

Citation: Khaiboullina SF, Abdulkhakov $S$ Khalikova A, Safina D, Martynova EV, Davidyuk $Y$, Khuzin F, Faizullina $R$, Lombardi VC, Cherepnev GV and Rizvanov AA (2016) Serum Cytokine

Signature That Discriminates

Helicobacter pylori Positive and Negative Juvenile Gastroduodenitis.

Front. Microbiol. 7:1916.

doi: 10.3389/fmicb.2016.01916
Gastroduodenitis caused by $\mathrm{H}$. pylori, often acquired in early childhood, is found in about $50 \%$ of the adult population. Although $H$. pylori infections can remain asymptomatic, its virulence factors usually trigger epithelial vacuolization and degeneration, loss of microvilli, disintegration of cytoplasm, and leukocyte accumulation. It is believed that leukocyte infiltration is driven by cytokines produced locally in infected tissue. However, so far little is known about changes in serum cytokines in juvenile patients infected with H. pylori. Serum cytokine profiles were analyzed in 62 juvenile patients diagnosed with gastroduodenitis using the Bio-Plex multiplex assay. $\mathrm{H}$. pylori infection was confirmed in 32 patients, while 30 patients were $\mathrm{H}$. pylori-free. Cytokines CXCL5 and CXCL6, potent neutrophil chemoattractants, were upregulated in all patients diagnosed with gastroduodenitis. Serum levels of IL8, a prototype neutrophil attractant, remained unchanged in subjects with gastroduodenitis relative to controls. Therefore, our data suggest that CXCL5 and CXCL6 play a role in directing neutrophil trafficking into inflamed gastroduodenal tissue. In addition, the CCL25/GM-CSF ratio differed significantly between $\mathrm{H}$. pylori-positive and -negative juveniles. Further, study is needed to evaluate the role of CCL25 and GM-CSF in the pathogenesis of the different etiologies of gastroduodenitis.

\section{Keywords: $\boldsymbol{H}$. pylori, virulence factors, cytokines, gastroduodenitis}

\section{INTRODUCTION}

Helicobacter pylori (H. pylori) was identified in 1982 and suggested to be a causative agent for gastritis and stomach ulcers (Marshall and Warren, 1984). This helix-shaped gram-negative bacterium colonizes gastric mucosa and persists as a chronic infection (Marshall et al., 1985a; Morris and Nicholson, 1987). H. pylori is one of the most common gastrointestinal infections, being found in about 50\% of the adult population (Sipponen et al., 1996; Kosunen et al., 1997). The majority of $\mathrm{H}$. pylori infections remain asymptomatic, with only $15 \%$ of carriers developing symptoms (Atherton, 1998; Ernst and Gold, 2000). Infection, often acquired in early childhood, 
has been shown to be associated with poor hygiene and impoverished living conditions (Malaty and Graham, 1994; Kivi et al., 2003; Konno et al., 2005; Dattoli et al., 2010). It is believed that $H$. pylori is transmitted via fecal-oral or oral-oral routes (Goh et al., 2011).

During gastric epithelium colonization, H. pylori establishes a persistent infection within the mucus layer without crossing the epithelial barrier (Noach et al., 1994). Infection is histologically characterized by surface epithelial degeneration, inflammation, and leukocyte infiltration into the gastric mucosa (Bodger and Crabtree, 1998; Peek et al., 2010).

$H$. pylori virulence factors are the main cause of tissue damage, and include vacuolating cytotoxin (vacA), cytotoxin associated gene A ( $\operatorname{cagA})$, and neutrophil-activating protein (HP-NAP; Atherton, 1998; Cellini and Donelli, 2000; Fu, 2014). Binding of VacA to gastric cells triggers epithelial vacuolization and degeneration, loss of microvilli, and cytoplasmic disintegration (Goodwin et al., 1986; Papini et al., 1994; Garner and Cover, 1996; Smoot et al., 1996). Animal studies have demonstrated that purified $v a c A$ toxin causes gastric epithelial damage with little effect on inflammatory leukocyte infiltration (Telford et al., 1994; Ghiara et al., 1995). In addition, cagA has been shown to be strongly associated with development of local inflammation and expression of pro-inflammatory cytokines (Peek et al., 1995). Moreover, it has been suggested that the cagA gene and nearby sequences code for proteins that act synergistically and promote production and secretion of pro-inflammatory cytokines (Tummuru et al., 1995; Censini et al., 1996), and that the virulence factor HP-NAP promotes neutrophil adhesion, chemotaxis, and activation (Satin et al., 2000). The combined effects of these virulence factors is inflammation of local tissue caused by damage to gastric epithelial cells, and activation of pro-inflammatory cytokine production.

Histologically, infiltration of gastric tissue by leukocytes is a hallmark of $H$. pylori infection. In tissue biopsies collected from patients infected with $H$. pylori both neutrophil infiltration (Kamada et al., 2006; Jaramillo-Rodríguez et al., 2011; Xu et al., 2012) and increased infiltration of CD4 $+\mathrm{T}$ helper lymphocytes in the lamina propria (D'Elios et al., 1997a) have been reported. Further, in gastric mucosa, it has been demonstrated that H. pylori infection activates predominantly Th1-type immune responses (D'Elios et al., 1997a), and immunohistochemically analyses of gastric biopsies have revealed an increased presence of CD8+ lymphocytes and macrophages (Bedoya et al., 2003). Animal models established that the early stage of infection is marked by neutrophil infiltration (Rossi et al., 2000). As infection progresses, a drop in neutrophil counts is followed by increased tissue infiltration with mononuclear leukocytes, mostly CD3+ lymphocytes. Initially scattered, lymphocyte infiltrates organize into small patches in the corpus and antrum of stomach (Rossi et al., 2000; Sepulveda and Patil, 2008). Later, the appearance of CD4+ and CD8+ lymphocytes in the periglandular area and beneath the basal lamina correlates with histological signs of gastric epithelial damage. Eventually, leukocyte infiltrates became organized in follicles containing $\mathrm{CD} 21+, \mathrm{CD} 4+$, and CD3+ lymphocytes (Rossi et al., 2000). Furthermore, the appearance of neutrophils at late stage leukocyte infiltration suggests active chronic gastritis. Together, these data indicate that initially $H$. pylori infection causes neutrophil infiltration of gastric mucosa, then as infection progresses neutrophils are replaced by lymphocytes. This leukocyte infiltration is the main cause of gastric epithelial damage in $H$. pylori infected tissue.

Exposure of gastric epithelium to $H$. pylori results in the production of a number of cytokines that stimulate migration of immune effector cells into inflamed tissue, including upregulation of IL8, CCL5, CCL3, IFN, IL10, IL12p40, and IL18 (Crabtree et al., 1994, 1995a,b; Yamaoka et al., 1996, 1998; Karttunen et al., 1997; Park et al., 2001; Dzierzanowska-Fangrat et al., 2008). Studies using animal models have demonstrated that the early stage of $H$. pylori infection is characterized by increased expression of IL1, IL8, IL6, and TNF- $\alpha$ in gastric mucosa (Harris et al., 2000; Rossi et al., 2000). Then, as the disease progresses, IL8 expression declines, while IL1, IL6, and TNF- $\alpha$ remain elevated (Rossi et al., 2000; Harris et al., 2000). It has been suggested that at late stages of the disease, there is a shift toward Th1 immunity, involving cytokines such as IFN $\gamma$ and IL12 (D'Elios et al., 1997a; Haeberle et al., 1997; Pellicanò et al., 2007), and that persistent activation of the Th1 immune response is a cause of tissue damage in H. pylori infection (D'Elios et al., 1997b; Smythies et al., 2000). A combination of transcriptional analysis of tissue biopsies and histological findings has provided most of the information about cytokine activation of $H$. pylori infection. However, there is limited knowledge of serum cytokine expression in children infected with $H$. pylori, since the majority of data is from adult populations (Bayraktaroğlu et al., 2004; Mehmet et al., 2004; Abdollahi et al., 2011; Eskandari-Nasab et al., 2013). To date, for the most part, cytokines studies have been limited to the Th1 or pro-inflammatory class. This is unfortunate, as H. pylori infection often occurs during early childhood establishing a lifelong chronic infection. Understanding cytokine expression at the initial stages of infection will identify early markers, and improve disease diagnosis.

Here, we present data on cytokine activation in serum of children with gastroduodenitis. Sixty-two juveniles with gastroduodenitis were included in this study, with 30 having a diagnosis of $H$. pylori infection. Regardless of the presence or absence of $H$. pylori pathogenicity markers, there was upregulation of the potent neutrophil chemoattractants, CXCL5, and CXCL6. However, serum levels of IL8, a prototype neutrophil attractant, were not statistically different between diagnoses. Therefore, our data suggest that a novel set of chemokines, CXCL5, and CXCL6, play a role in neutrophil trafficking into inflamed gastroduodenal tissue. Further, an intriguing observation was that the CCL25/GM-CSF ratio differed significantly between $H$. pylori positive and negative children with gastroduodenitis.

\section{MATERIALS AND METHODS \\ Subjects}

Sixty-two patients (24 boys, 38 girls; age $14.0 \pm 2.1$ ) hospitalized in the Children's Republican Clinical Hospital (Kazan, Russia) with a diagnosis of gastritis and duodenitis were recruited for this study. Initial diagnosis of $H$. pylori infection in 30 of the patients 
was based on clinical presentation and upper GI endoscopy. The presence of $H$. pylori was confirmed by urea breath test and PCR.

Biopsies were collected from each patient during upper GI tract endoscopy: two from antral part of the stomach along the major and minor curvatures, and 2-3 from the body of the stomach, along the major and minor curvatures. In addition, stomach biopsies were collected from three controls, who were found to be negative for any gastroduodenal pathology by diagnostic upper GI tract endoscopy. Biopsies were used for both PCR analyses and histological studies.

Serum samples were collected from all 62 juveniles with gastritis and duodenitis, as well as from 20 age- and sex-matched controls. All controls were negative for symptoms of upper GI tract infection or gastritis. Serum samples were stored at $-80^{\circ} \mathrm{C}$. The Ethics Committee of Kazan State Medical University approved this study (N6, 06.25.2012) and informed consent was obtained from the legal guardian of each study subject, in accordance with the Declaration of Helsinki and the article 20, Federal Law "Protection of Health Right of Citizens of Russian Federation” (N323-Ф3, 11.21.2011).

\section{Urea Breath Test}

Breath ID Hp (Exalenz, USA) was used to confirm $H$. pylori infection. This breath test measures the presence of ${ }^{13} \mathrm{C}$ labeled $\mathrm{CO}_{2}$ in the patient's breath after ingestion of a solution containing ${ }^{13} \mathrm{C}$ labeled urea. After $10 \mathrm{~min}$, exhaled air is collected and tested for the presence of ${ }^{13} \mathrm{CO}_{2}$, which indicates $H$. pylori infection.

\section{PCR Detection of $\boldsymbol{H}$. pylori}

DNA was extracted from biopsy tissue using the Helicopol Kit (Lytech, Moscow). H. pylori positive biopsies were analyzed by PCR for a pathogenicity marker profile using the Helicopol II Kit (Lytech, Moscow). Briefly, $2 \mu$ total DNA was mixed with $4 \mu l$ 10x PCR buffer, $2 \mu l 25$ mM MgCl $2,0.5 \mu l$ (100 pmol) each of primers, $40.7 \mu \mathrm{l}$ distilled water, and $0.3 \mu \mathrm{l}(2.5 \mathrm{U})$ Taq DNA polymerase. The reaction mixture was then subjected to 35 cycles, each consisting of $30 \mathrm{~s}$ at $94^{\circ} \mathrm{C}, 30 \mathrm{~s}$ at $50^{\circ} \mathrm{C}$, and $2 \mathrm{~min}$ at $72^{\circ} \mathrm{C}$. PCR products were analyzed on a $1 \%$ agarose gel.

\section{Cytokine Analysis}

Serum cytokine levels were analyzed using a Bio-Plex Pro Human Chemokine Panel (40-Plex; Bio-Rad, Hercules, CA), a multiplex magnetic bead-based antibody detection kit.

\section{Immunohistochemical Analysis}

After initial analysis, there were surplus clinical diagnostic biopsy specimens from $21 \mathrm{H}$. pylori positive and 13 negative cases. These were used for immmunohistochemical analysis. Punch biopsies were fixed in $4 \%$ paraformaldehyde for $4 \mathrm{~h}$ at $4^{\circ} \mathrm{C}$, and then cryoprotected with $30 \%$ sucrose in PBS. Immunohistochemical staining was performed on $5 \mu \mathrm{m}$ thick sections. Slides were deparaffinized with xylene and rehydrated through a graded alcohol series. Tissue morphology was evaluated by light microscopy using hematoxylin-eosin staining. Additionally, Alcian blue ( $\mathrm{pH}$ 2.5) and periodic acid Schiff (PAS) staining were performed to detect the presence of sialomucins.

\section{Statistical Analysis}

Statistical analysis was performed using the STATISTICA 7.0 Software Package (StatSoft, Tulsa, OK) and the IBM SPSS Statistics 20 Software Package (IBM Corp, Armonk, NY, U.S.). Data are presented as the median (5-95\% range) for continuous variables. Differences between independent study groups were tested by non-parametric methods. To address type 1 error, Kruskal-Wallis ANOVA by Ranks test for multiple independent samples was followed by the multiple comparison (all pairs) nonparametric post-hoc Steel-Dwass test Nonparametric multiple comparisons were made [recalculated and confirmed] by the Steel-Dwass all pairs test using JMP ${ }^{\circledR}$ 13.0.0 Software (SAS Institute Inc, USA). Differences were considered significant at $P<0.05$. Jonckheere's non-parametric trend test was performed to compare three group medians when they were arranged in order. Cytokine profiles between subject groups were differentiated using forward stepwise discriminant function analysis.

\section{RESULTS}

\section{Patients}

Sixty-two patients ( 24 boys and 38 girls) were admitted to the Children's Republican Clinical Hospital (Kazan, Russia) with a diagnosis of gastritis and duodenitis. The main symptoms were pain in the epigastric area, vomiting, nausea, headache, and fatigue. Biopsy samples collected from the antrum of the stomach were analyzed for the presence of $H$. pylori antigens. Thirty samples were positive for $H$. pylori and 32 samples negative. The surplus biopsy tissue from 21 positive and 13 negative juveniles (of the 62 enrolled in the study) was used for histological studies.

Three H. pylori positive biopsies had massive leukocyte infiltration of the lamina propria (Figure 1) with moderate incomplete metaplasia of the epithelium (Figure 2). Moderate lymphocyte infiltration of the lamina propria was found in 11 positive biopsies, with four having moderate epithelial metaplasia. Finally, four had moderate lymphocyte infiltration of the lamina propria with no sign of metaplasia. Based on histological evaluation, diagnosis of chronic atrophic gastritis was established in 9 (42.9\%) of the $H$. pylori positive biopsies.

Histological analysis of the $13 \mathrm{H}$. pylori negative biopsies revealed epithelial metaplasia in eight biopsies, with lymphocyte infiltration in five cases. Two biopsies had lymphocyte infiltration and metaplasia. The remaining two biopsies had no sign of lymphocyte infiltration or metaplasia. Diagnosis of chronic atrophic gastritis was established in $6(46.2 \%)$ of the $H$. pylori negative biopsies. The gastritis activity was graded in all biopsies according to the Histological Division of the Sydney System and "Up-Dated Sydney System" (Tytgat, 1991; Dixon et al., 1997; Table 1). This classification determines the activity grade based on the presence of polymorphonuclear leucocytes in combination with mononuclear inflammatory infiltrate, intestinal metaplasia, atrophy, and detection of $H$. pylori organisms. H. pylori positive biopsies were characterized by a higher grade of chronic inflammation compared to $H$. pylori-free biopsies (Table 1).

All patients were examined by gastroduodenoscopy. Hyperemia and edema were detected in the gastric mucosa 

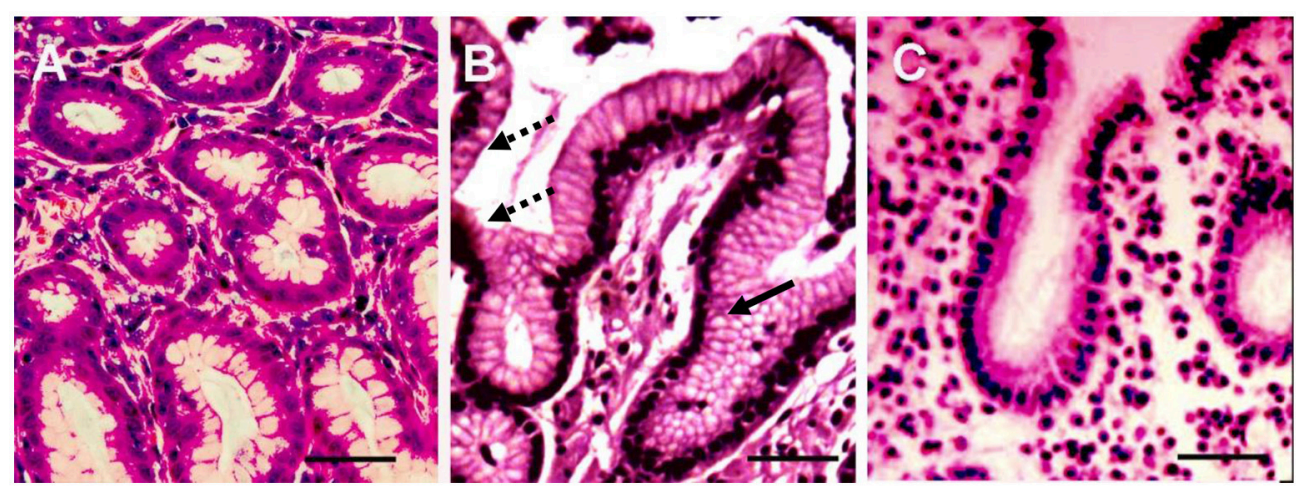

FIGURE 1 | Histological sections of three representative biopsies. Gastric biopsy sections (3-5 $\mu \mathrm{m})$ of control (A), and $H$. pylori positive (B) and $H$. pylori negative (C) gastroduodenitis cases were deparaffinized and stained with hematoxylin and eosin (H\&E). The gastric epithelium phenotype of the $H$. pylori positive juvenile (B) resembles the phenotype of colonic epithelium, characterized by multiple intracytoplasmic mucin droplets of varying sizes and shapes (solid arrow), and the absence of a brush border (dashed arrow). H\&E; x100; Bar represents $20 \mu \mathrm{m}$.

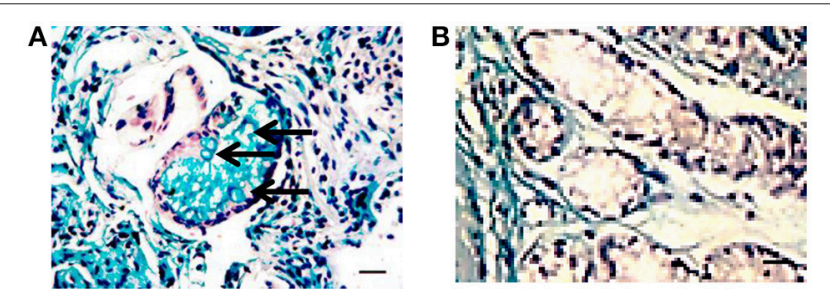

FIGURE 2 | Histochemistry of gastric epithelium metaplasia in a H. pylori positive biopsy. Gastric biopsy sections $(3-5 \mu \mathrm{m})$ were deparaffinized and stained with Alcian blue $(\mathrm{pH} 2.5)$ and PAS followed by H\&E staining. Presence of sialomucins (stained blue, solid arrow) demonstrates incomplete metaplasia (Filipe et al., 1994). (A) H. pylori positive gastric biopsy; (B) H. pylori negative gastric biopsy (Bar represents $20 \mu \mathrm{m}$ ).

of some, but not all, subjects. No visible changes were observed in the esophagus. Erosion with fibrin deposits, hyperemia, and edema were detected in 3 (14\%) of $H$. pylori positive subjects. Five (16.1\%) H. pylori positive cases were characterized by duodenal bulbar deformity with multiple scars, hyperemia and edema, with no deformation, or scarring observed in $H$. pylori negative stomachs. Two (6.4\%) H. pylori positive stomachs had multiple ulcers, while all $H$. pylori negative patients were all ulcer-free. Overall, $H$. pylori positive stomachs were characterized by pronounced histological abnormalities compared to H. pylori negative stomachs.

\section{Cytokine Profile}

A total of 40 cytokines were analyzed in the serum of all subjects (Table 2). Children with gastroduodenitis had similar profiles, with the cytokine activation profile in $H$. pylori positive serum closely resembling $H$. pylori negative. For example, significant upregulation of CXCL2, CCL1, IL2, CCL7, CCL22, CXCL16, and CXCL12 was detected in both groups. Interestingly, the serum level of a major chemoattractant for neutrophils, IL8, did not differ significantly between patients with gastroduodenitis and controls. However, serum levels of CXCL5 and CXCL6, chemoattractant factors for neutrophils, were significantly upregulated in sera from all $H$. pylori positive juveniles, and not linked to the presence of neutrophil infiltration in biopsied tissue. Although serum levels of TNF- $\alpha$ were significantly higher in both $H$. pylori positive and negative sera compared to controls (Table 2), concentrations of this cytokine were within the normal range for this age (Mózes et al., 2011).

Significantly increased levels of CCL15, CCL20, and MIF were detected in both $H$. pylori positive and negative serum compared controls. However, only MIF levels differed significantly between the two groups. In contrast, no changes in serum levels of CCL2, CCL3, CCL8, CCL11, CCL17, CCL19, CCL21, CCL23, CCL24, CCL26, CCL27, CXCL9, CX3CL1, IL6, IL8, IL10, and IFN- $\gamma$ were found either between the two groups of patients with gastroduodenitis, or between juveniles with gastroduodenitis and the control group.

We compared cytokine activation in $H$. pylori positive patients with different histological presentations. The histological data was used to divide the patients into four groups; group one was characterized by severe lymphocyte and neutrophil infiltration of the lamina propria with moderate epithelial metaplasia, group two had moderate lymphocyte infiltration of the lamina propria and moderate epithelial metaplasia, group three had mild infiltration of lamina propria and mild epithelial metaplasia, and group four had no lymphocyte infiltration and no epithelial metaplasia. The pattern of cytokine upregulation was similar in all groups and was characterized by increased serum levels of chemoattractants for lymphocytes, monocytes, natural killer cells and dendritic cells such as CCL1, CCL22, CCL15, CXCL16, and CXCL12.

Next, forward stepwise discriminant function analysis was utilized to identify cytokines that differed between control and H. pylori positive and negative sera. Fourteen cytokines were selected to generate a classification matrix [model summary: Wilks' lambda $=0.15498 ; F_{(28,102)}=5.6106, p<0.0001$, IL4, IL8, CCL3, CCL1, CCL7, IFN $\gamma$, CXCL12, CCL2, CXCL10, 
TABLE 1 | Histological examination of the gastric biopsies from $\boldsymbol{H}$. pylori positive and negative gastroduodenitis cases.

\begin{tabular}{|c|c|c|c|}
\hline Histological findings & $\begin{array}{c}\text { H. pylori positive, abs. } \\
(\%), n=21\end{array}$ & $\begin{array}{c}\text { H. pylori negative, abs. } \\
(\%), n=13\end{array}$ & Control abs. (\%) $n=3$ \\
\hline No visible lymphocyte infiltration or few inflammatory cells & $9(42.9 \%)$ & $12(92.3 \%)$ & $3(100 \%)$ \\
\hline Moderate leukocyte infiltration of the lamina propria (Grade I) & $9(42.9 \%)$ & $1(7.7 \%)$ & - \\
\hline Severe leukocyte infiltration of the lamina propria (Grade II) & $3(14.2 \%)$ & 0 & - \\
\hline Metaplasia (+) & $12(57.1 \%)$ & $8(61.5 \%)$ & - \\
\hline Metaplasia (-) & $9(42.9 \%)$ & $5(38.5 \%)$ & $3(100 \%)$ \\
\hline
\end{tabular}

CCL23, MIF, TNF- $\alpha$, CXCL1, and CXCL9]. Discriminant analysis revealed greater differences between patients with gastroduodenitis (both $H$. pylori positive and negative) and controls (Squared Mahalanobis distances 34.32) than between H. pylori positive and negative patients (Squared Mahalanobis distances 2.56). Furthermore, the 14 cytokine-based classification matrix yielded $100 \%$ correct predictions for controls (predicted classifications vs. observed classifications in the classification matrix), with lower percentages of correct predictions for cases that were $H$. pylori positive $(80 \%)$ and $H$. pylori negative (76.66\%).

In Crohn's disease altered expression of GM-CSF and CCL25 has been suggested to play a role in the pathogenesis of inflammatory gastrointestinal disease (Samson et al., 2011). Therefore, we sought to determine whether these two cytokines were involved in the pathogenesis of $H$. pylori-related gastroduodenitis. Serum levels of GM-CSF were significantly upregulated in $H$. pylori negative subjects, while in $H$. pylori positive subjects, GM-CSF levels were similar to controls (Table 2), and significantly lower $\left({ }^{*} P<0.05\right.$; Table 2$)$ than $H$. pylori-free serum. In addition to increased GM-CSF levels, $H$. pylori negative serum was characterized by significantly lower levels of CCL25 (Table 2), suggesting bidirectional activation of these cytokines in negative serum. To further analyze the activation pattern of these cytokines in $H$. pylori negative and positive serum, we compared the CCL25/GM-CSF ratio in three independent study groups using Kruskal-Wallis ANOVA by Ranks test $(P$-level $=0.0083)$, followed by post-hoc Jonckheere's non-parametric trend test for multiple comparisons $(P$-level $=0.006$; Figure 3$)$. The CCL25/GM-CSF ratio differed significantly between each group. $H$. pylori positive and negative juveniles were positioned on either side of controls (Figure 3), suggesting that the CCL25/GM-CSFratio reflects an essential difference in gastroduodenitis pathogenesis with $H$. pylori positive and negative stomach having distinct forms.

\section{DISCUSSION}

H. pylori infection is often acquired early in childhood (McCallion et al., 1996; Suerbaum and Michetti, 2002; Tkachenko et al., 2007). This bacterium colonizes gastric mucosal epithelium, establishes a chronic infection (Marshall et al., 1985b; Morris and Nicholson, 1987), and once established, releases numerous virulence factors causing apoptosis and vacuolization of the gastric epithelium, and functional disruption of the gastric epithelial barrier (Goodwin et al., 1986; Papini et al., 1994; Garner and Cover, 1996; Smoot et al., 1996).

Currently, little is known about systemic activation of cytokines in children infected with $H$. pylori. The serum cytokine profile of infected children suggests a strong activation of chemoattractants for mononuclear leukocytes (Table 2). For example, in $H$. pylori positive gastroduodenitis we demonstrate increased serum levels of chemoattractants for mononuclear lymphocytes, such as CXCL10, CCL22, and CXCL16 (Taub et al., 1996; Andrew et al., 1998; Huang et al., 2008). This observation is supported by histological examination of biopsies, where increased leukocyte infiltration was detected (Table 1 and Figure 1). Interestingly, there were no differences in the serum cytokine profiles of patients with distinct histological presentations suggesting that tissue pathology is determined by in situ cytokine activation, which is not reflected in circulating cytokine levels. Serum levels of the prototype neutrophil chemoattractant IL8 (Gessler et al., 2004), remained unchanged in juveniles with gastroduodenitis. Bayraktaroglu et al described the same phenomenon in adults where IL-8 serum levels in $H$. pylori positive cases did not differ from controls (Bayraktaroğlu et al., 2004). However, increased levels of IL8 transcripts in tissue have been documented in $H$. pylori patients (Yamada et al., 2013; Nagashima et al., 2015), suggesting that upregulation of IL-8 may be a local characteristic of inflammation of gastrointestinal tissue. The molecular mechanisms regulating systemic neutrophil migration into inflamed tissue remains to be determined. Here, we demonstrate upregulation of CXCL5 and CXCL6, potent chemoattractants for neutrophils (Territo et al., 1989; Chertov et al., 1996; Mei et al., 2012) in serum from juveniles with gastroduodenitis. CXCL5, constitutively expressed by enterocytes, coordinates with CXCR2 the transmigration of neutrophils (Mei et al., 2012). Increased numbers of CXCL6 positive mucosal cells have been observed in Crohn's disease biopsies (Yamada et al., 2013), where, upon activation, upregulation of CXCL6 is more sustained than IL8 (Wuyts et al., 2003). It has been suggested that CXCL6 could play a role in supporting chronic inflammation by facilitating neutrophil migration at a late stage of infection (Wuyts et al., 2003). In this study, we present novel data on the upregulation of CXCL5 and CXL6 in serum during gastroduodenitis. Serum levels of these cytokines did not differ between $H$. pylori positive and negative children with gastroduodenitis, suggesting that upregulation of CXCL5 and CXCL6 is a tissue-specific response to inflammation, and not driven by a specific pathogen. 
TABLE 2 | Serum cytokine profile of children diagnosed with $H$. pylori positive and negative gastroduodenitis.

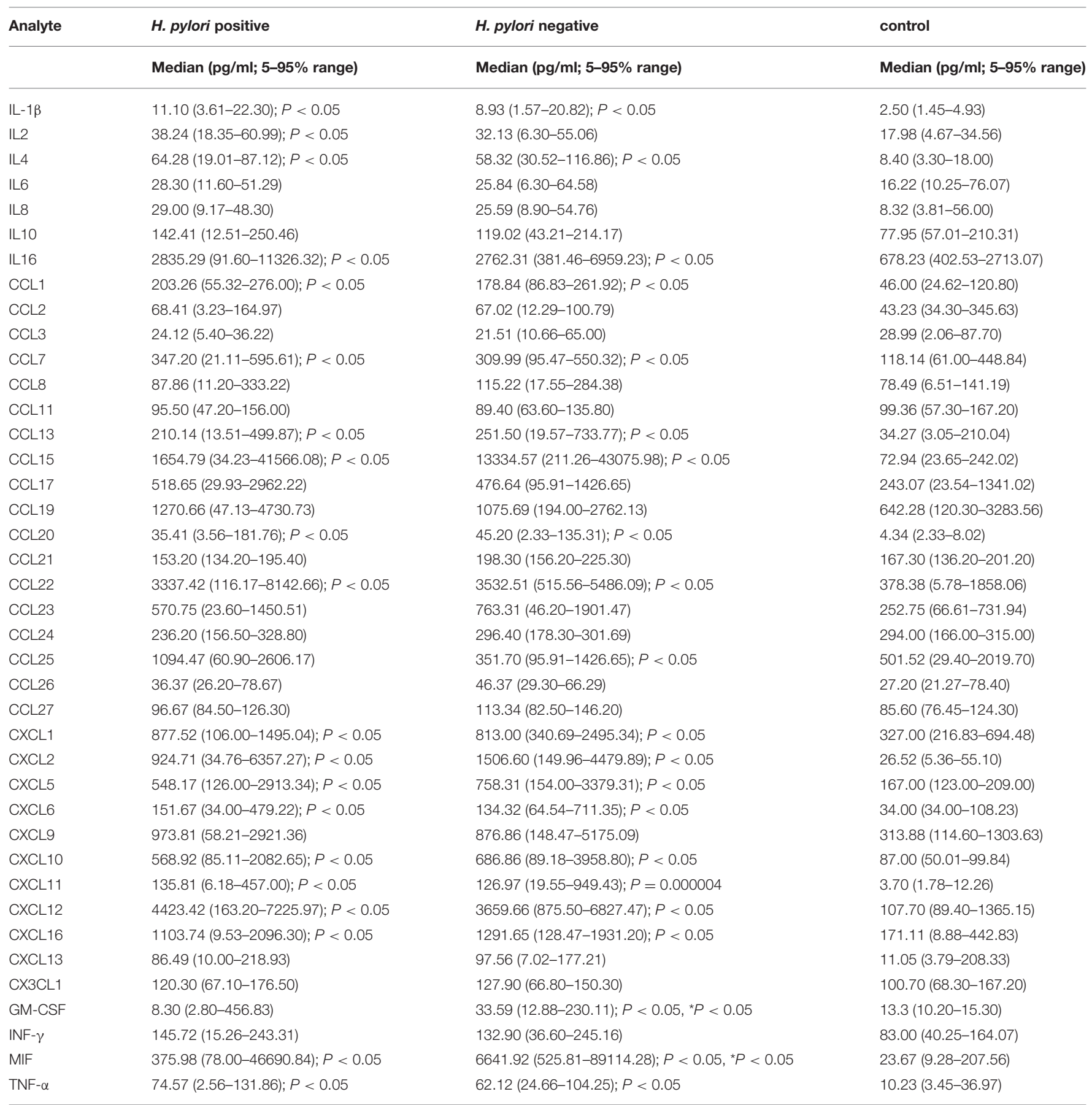

$P$-significance between gastroduodenitis group and healthy control, Steel-Dwass test.

${ }^{*} P$-significance gastroduodenitis groups, Steel-Dwass test.

CXCL6 is a neutrophil chemoattracting factor produced by endothelial cells and macrophages exposed to IL1 $\beta$ or LPS (Wuyts et al., 2003). Additionally, transcriptional activation of both CXCL6 and CXCL5 has been demonstrated in cells stimulated with IL17 (Ruddy et al., 2004; Numasaki et al., 2005). Here, we show upregulation of IL17 in H. pylori positive juveniles suggesting that IL17 activation of epithelial cells and local macrophages causes upregulation of CXCL5 and CXCL6, which in turn promotes neutrophil chemotaxis into gastric tissue. It should be noted that CXCL6 synergy with MCP1 facilitates neutrophil chemotaxis (Gijsbers et al., 2005). Therefore, neutrophil chemotaxis may result from a combined action of several of cytokines. 


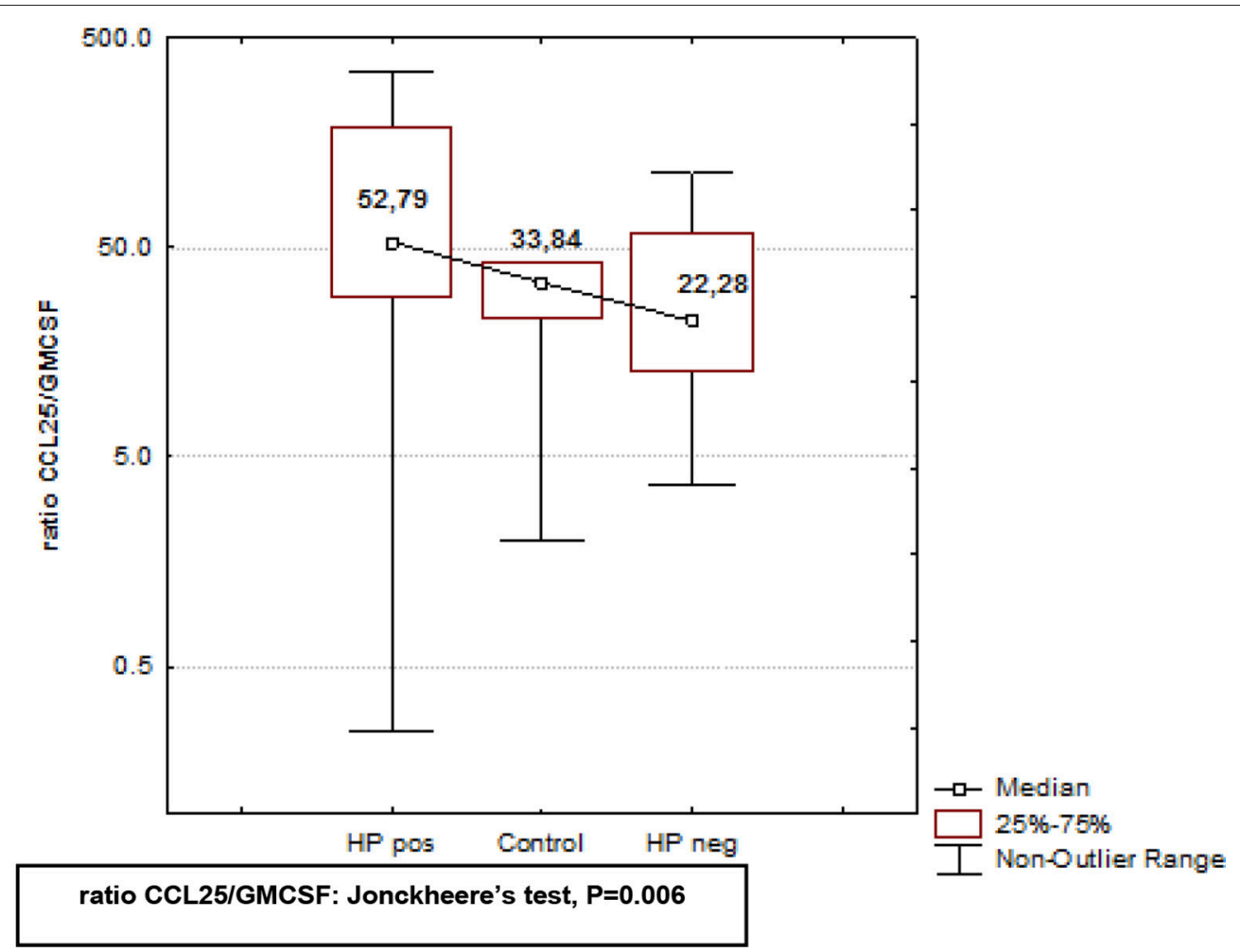

FIGURE 3 | Analysis of CCL25/GMCSF ratio in $\boldsymbol{H}$. pylori positive and negative subjects, and healthy controls. CCL25/GMCSF ratio in serum of H. pylori positive, H. pylori negative, and healthy controls was analyzed using using Kruskal-Wallis ANOVA by Ranks test, followed by the post-hoc non-parametric Jonckheere's-test for ordered medians. CCL25/GM-CSF ratio differed significantly between $H$. pylori positive and $H$. pylori negative subjects, and healthy controls $(P=0.006)$.

The most intriguing observation made in this study was that GM-CSF and CCL25 may play a role in the pathogenesis of gastroduodenitis, and that changes in serum levels of GM-CSF and CCL25 may reflect the host's reaction to disease. Analysis of the CCL25/GM-CSF ratio indicates that $H$. pylori positive and negative gastroduodenitis are unrelated clinical entities. Our data support the observation made by Samson et al. suggesting a role for GM-CSF and CCL25 in the pathogenesis of inflammatory gastrointestinal disease (Samson et al., 2011). These authors demonstrated that CD patients with high serum level of GM-CSF neutralizing antibodies had increased number of iliac epithelial cells expressing CCL25. Local upregulation of CCL25 has been shown to facilitate iliac inflammation by stimulating CCR9-driven $\mathrm{T}$ lymphocyte migration. Our data provide further evidence for a role of both CCL25 and GM-CSF in the pathogenesis of inflammatory gastrointestinal diseases. Although our analysis revealed no correlation between the CCL25/GMCSF ratio, histological presentation, and localization of gastrointestinal inflammation, we believe further study should be conducted to fully understand the function of CCL5 and GM-CSF in the pathogenesis of inflammatory gastrointestinal disease.

We have demonstrated upregulation of serum CXCL5 and CXCL6 in subjects diagnosed with gastroduodenitis, whereas serum levels of the neutrophil attractant, IL8, did not differ from controls. Therefore, we suggest that neutrophil accumulation in tissue in children with gastroduodenitis is directed by a distinct set of chemokines including CXCL5 and CXCL6. Additionally, we present the first evidence for a potential role for CCL25 and GM-CSF in the pathogenesis of gastroduodenitis, and that the CCL25/GM-CSF ratio can be utilized to for the discrimination of gastroduodenitis caused by $H$. pylori from gastroduodenitis due to other causes. Further study, using animal model for $H$. pylori gastroduodenitis is needed to determine the roles of CCL25 and GM-CSF in the pathogenesis of gastroduodenitis.

\section{AUTHOR CONTRIBUTIONS}

SK, AR, VL, EM-cytokine profile analysis, SA, AK, DS, RFclinical examination of patients, FK-morphology, YD and GCbiostatistics.

\section{ACKNOWLEDGMENTS}

The work was performed according to the Russian Government Program of Competitive Growth of Kazan Federal University and subsidy allocated to Kazan Federal University for the 
state assignment in the sphere of scientific activities. Some of the experiments were conducted with support of the Interdisciplinary center for collective use of Kazan Federal University supported by Ministry of Education of Russia (ID
RFMEFI59414X0003), Interdisciplinary Center for Analytical Microscopy and Pharmaceutical Research and Education Center, Kazan (Volga Region) Federal University, Kazan, Russia.

\section{REFERENCES}

Abdollahi, H., Shams, S., Zahedi, M. J., Darvish Moghadam, S., Hayatbakhsh, M. M., and Jafarzadeh, A. (2011). IL-10, TNF- $\alpha$ and IFN- $\gamma$ levels in serum and stomach mucosa of Helicobacter pylori-infected patients. Iran. J. Allergy Asthma Immunol. 10, 267-271. doi: 10.04/ijaai.267271

Andrew, D. P., Chang, M. S., McNinch, J., Wathen, S. T., Rihanek, M., Tseng, J., et al. (1998). STCP-1 (MDC) CC chemokine acts specifically on chronically activated Th2 lymphocytes and is produced by monocytes on stimulation with Th2 cytokines IL-4 and IL-13. J. Immunol. 161, 5027-5038.

Atherton, J. C. H. (1998). pylori virulence factors. Br. Med. Bull. 54, 105-120. doi: 10.1093/oxfordjournals.bmb.a011662

Bayraktaroğlu, T., Aras, A. S., Aydemir, S., Davutoğlu, C., Ustündağ, Y., Atmaca, H., et al. (2004). Serum levels of tumor necrosis factor-alpha, interleukin-6 and interleukin-8 are not increased in dyspeptic patients with Helicobacter pylori-associated gastritis. Mediators Inflamm. 13, 25-28. doi: $10.1080 / 09629350410001664789$

Bedoya, A., Garay, J., Sanzón, F., Bravo, L. E., Bravo, J. C., Correa, H., et al. (2003). Histopathology of gastritis in Helicobacter pylori-infected children from populations at high and low gastric cancer risk. Hum. Pathol. 34, 206-213. doi: 10.1053/hupa.2003.43

Bodger, K., and Crabtree, J. E. (1998). Helicobacter pylori and gastric inflammation. Br. Med. Bull. 54, 139-150. doi: 10.1093/oxfordjournals.bmb.a011664

Cellini, L., and Donelli, G. (2000). Virulence Factors of Helicobacter pylori. Microb. Ecol. Health. Dis. Suppl. 2, 259-262. Available online at: http://www. microbecolhealthdis.net/index.php/mehd/article/viewFile/8058/9396

Censini, S., Lange, C., Xiang, Z., Crabtree, J. E., Ghiara, P., Borodovsky, M., et al. (1996). cag, a pathogenicity island of Helicobacter pylori, encodes type I-specific and disease-associated virulence factors. Proc. Natl. Acad. Sci. U.S.A. 93, 14648-14653.

Chertov, O., Michiel, D. F., Xu, L., Wang, J. M., Tani, K., Murphy, W. J., et al. (1996). Identification of defensin-1, defensin-2, and CAP37/azurocidin as T-cell chemoattractant proteins released from interleukin-8-stimulated neutrophils. J. Biol. Chem. 271, 2935-2940.

Crabtree, J. E., Covacci, A., Farmery, S. M., Xiang, Z., Tompkins, D. S., Perry, S., et al. (1995a). Helicobacter pylori induced interleukin-8 expression in gastric epithelial cells is associated with CagA positive phenotype. J. Clin. Pathol. 48, 41-45.

Crabtree, J. E., Farmery, S. M., Lindley, I. J., Figura, N., Peichl, P., and Tompkins, D. S. (1994). CagA/cytotoxic strains of Helicobacter pylori and interleukin-8 in gastric epithelial cell lines. J. Clin. Pathol. 47, 945-950.

Crabtree, J. E., Xiang, Z., Lindley, I. J., Tompkins, D. S., Rappuoli, R., and Covacci, A. (1995b). Induction of interleukin-8 secretion from gastric epithelial cells by a cagA negative isogenic mutant of Helicobacter pylori. J. Clin. Pathol. 48, 967-969.

Dattoli, V. C., Veiga, R. V., da Cunha, S. S., Pontes-de-Carvalho, L. C., Barreto, M. L., and Alcântara-Neves, N. M. (2010). Seroprevalence and potential risk factors for Helicobacter pylori infection in Brazilian children. Helicobacter 15, 273-278. doi: 10.1111/j.1523-5378.2010.00766.x

D'Elios, M. M., Manghetti, M., Almerigogna, F., Amedei, A., Costa, F., Burroni, D., et al. (1997b). Different cytokine profile and antigen-specificity repertoire in Helicobacter pylori-specific $\mathrm{T}$ cell clones from the antrum of chronic gastritis patients with or without peptic ulcer. Eur. J. Immunol. 27, 1751-1755.

D’Elios, M. M., Manghetti, M., De Carli, M., Costa, F., Baldari, C. T., Burroni, D., et al. (1997a). T helper 1 effector cells specific for Helicobacter pylori in the gastric antrum of patients with peptic ulcer disease. J. Immunol. 158, 962-967.

Dixon, M. F., Genta, R. M., Yardley, J. H., and Correa, P. (1997). Histological classification of gastritis and Helicobacter pylori infection: an agreement at last?
The International Workshop on the Histopathology of Gastritis. Helicobacter. 2(Suppl. 1), S17-24.

Dzierzanowska-Fangrat, K., Michalkiewicz, J., Cielecka-Kuszyk, J., Nowak, M., Celinska-Cedro, D., Rozynek, E., et al. (2008). Enhanced gastric IL-18 mRNA expression in Helicobacter pyloriinfected children is associated with macrophage infiltration, IL-8, and IL-1 beta mRNA expression. Eur. J. Gastroenterol. Hepatol. 20, 314-319. doi: 10.1097/MEG.0b013e3282f340da

Ernst, P. B., and Gold, B. D. (2000). The disease spectrum of Helicobacter pylori: the immunopathogenesis of gastroduodenal ulcer and gastric cancer. Annu. Rev. Microbiol. 54, 615-640. doi: 10.1146/annurev.micro.54.1.615

Eskandari-Nasab, E., Sepanjnia, A., Moghadampour, M., Hadadi-Fishani, M., Rezaeifar, A., Asadi-Saghandi, A., et al. (2013). Circulating levels of interleukin (IL)-12 and IL-13 in Helicobacter pyloriinfected patients, and their associations with bacterial CagA and VacA virulence factors. Scand. J. Infect. Dis. 45, 342-349. doi: 10.3109/00365548.2012.737930

Filipe, M. I., Muñoz, N., Matko, I., Kato, I., Pompe-Kirn, V., Jutersek, A., et al. (1994). Intestinal metaplasia types and the risk of gastric cancer: a cohort study in Slovenia. Int. J. Cancer 57, 324-329. doi: 10.1002/ijc.2910570306

$\mathrm{Fu}, \mathrm{H}$. W. (2014). Helicobacter pylori neutrophil-activating protein: from molecular pathogenesis to clinical applications. World J. Gastroenterol. 20, 5294-5301. doi: 10.3748/wjg.v20.i18.5294

Garner, J. A., and Cover, T. L. (1996). Binding and internalization of the Helicobacter pylori vacuolating cytotoxin by epithelial cells. Infect. Immun. 64, 4197-4203.

Gessler, P., Pretre, R., Hohl, V., Rousson, V., Fischer, J., and Dahinden, C. (2004). CXC-chemokine stimulation of neutrophils correlates with plasma levels of myeloperoxidase and lactoferrin and contributes to clinical outcome after pediatric cardiac surgery. Shock 22, 513-520. doi: 10.1097/01.shk.0000145939.54838.51

Ghiara, P., Marchetti, M., Blaser, M. J., Tummuru, M. K., Cover, T. L., Segal, E. D., et al. (1995). Role of the Helicobacter pylori virulence factors vacuolating cytotoxin, CagA, and urease in a mouse model of disease. Infect. Immun. 63, 4154-4160.

Gijsbers, K., Gouwy, M., Struyf, S., Wuyts, A., Proost, P., Opdenakker, G., et al. (2005). GCP-2/CXCL6 synergizes with other endothelial cellderived chemokines in neutrophil mobilization and is associated with angiogenesis in gastrointestinal tumors. Exp. Cell. Res. 303, 331-342. doi: 10.1016/j.yexcr.2004.09.027

Goh, K. L., Chan, W. K., Shiota, S., and Yamaoka, Y. (2011). Epidemiology of Helicobacter pylori infection and public health implications. Helicobacter 16(Suppl. 1), 1-9. doi: 10.1111/j.1523-5378.2011.00874.x

Goodwin, C. S., Armstrong, J. A., and Marshall, B. J. (1986). Campylobacter pyloridis, gastritis, and peptic ulceration. J. Clin. Pathol. 39, 353-365. doi: 10.1136/jcp.39.4.353

Haeberle, H. A., Kubin, M., Bamford, K. B., Garofalo, R., Graham, D. Y., El-Zaatari, F., et al. (1997). Differential stimulation of interleukin-12 (IL-12) and IL-10 by live and killed Helicobacter pylori in vitro and association of IL-12 production with gamma interferon-producing $\mathrm{T}$ cells in the human gastric mucosa. Infect. Immun. 65, 4229-4235.

Harris, P. R., Smythies, L. E., Smith, P. D., and Dubois, A. (2000). Inflammatory cytokine mRNA expression during early and persistent Helicobacter pylori infection in nonhuman primates. J. Infect. Dis. 181, 783-786. doi: $10.1086 / 315257$

Huang, Y., Zhu, X. Y., Du, M. R., and Li, D. J. (2008). Human trophoblasts recruited $\mathrm{T}$ lymphocytes and monocytes into decidua by secretion of chemokine CXCL16 and interaction with CXCR6 in the first-trimester pregnancy. J. Immunol. 180, 2367-2375. doi: 10.4049/jimmunol.180.4.2367

Jaramillo-Rodríguez, Y., Nares-Cisneros, J., Martínez-Ordaz, V. A., VelascoRodríguez, V. M., Márquez, F. C., and Manríquez-Covarrubias, L. E. (2011). Chronic gastritis associated with Helicobacter pylori in Mexican 
children: histopathological patterns. Pediatr. Dev. Pathol. 14, 93-98. doi: 10.2350/09-12-0754-OA.1

Kamada, T., Sugiu, K., Hata, J., Kusunoki, H., Hamada, H., Kido, S., et al. (2006). Evaluation of endoscopic and histological findings in Helicobacter pylori positive Japanese young adults. J. Gastroenterol. Hepatol. 21(1 Pt 2), 258-61. doi: 10.1111/j.1440-1746.2006.04128.x

Karttunen, R. A., Karttunen, T. J., Yousfi, M. M., el-Zimaity, H. M., Graham, D. Y., and el-Zaatari, F. A. (1997). Expression of mRNA for interferon-gamma, interleukin-10, and interleukin-12 (p40) in normal gastric mucosa and in mucosa infected with Helicobacter pylori. Scand. J. Gastroenterol. 32, 22-27. doi: 10.3109/00365529709025058

Kivi, M., Tindberg, Y., Sörberg, M., Casswall, T. H., Befrits, R., Hellström, P. M., et al. (2003). Concordance of Helicobacter pylori strains within families. J. Clin. Microbiol. 41, 5604-5608. doi: 10.1128/JCM.41.12.5604-5608.2003

Konno, M., Fujii, N., Yokota, S., Sato, K., Takahashi, M., Sato, K., et al. (2005). Five-year follow-up study of mother-to-child transmission of Helicobacter pylori infection detected by a random amplified polymorphic DNA fingerprinting method. J. Clin. Microbiol. 43, 2246-2250. doi: 10.1128/JCM.43.5.2246-2250.2005

Kosunen, T. U., Aromaa, A., Knekt, P., Salomaa, A., Rautelin, H., Lohi, P., et al. (1997). Helicobacter antibodies in 1973 and 1994 in the adult population of Vammala, Finland. Epidemiol. Infect. 119, 29-34. doi: $10.1017 /$ S0950268897007565

Malaty, H. M., and Graham, D. Y. (1994). Importance of childhood socioeconomic status on the current prevalence of Helicobacter pylori infection. Gut 35, 742-745. doi: 10.1136/gut.35.6.742

Marshall, B. J., and Warren, J. R. (1984). Unidentified curved bacilli in the stomach of patients with gastritis and peptic ulceration. Lancet 1, 1311-1315. doi: 10.1016/S0140-6736(84)91816-6

Marshall, B. J., Armstrong, J. A., McGechie, D. B., and Glancy, R. J. (1985b). Attempt to fulfil Koch's postulates for pyloric Campylobacter. Med. J. Aust. 142, 436-439.

Marshall, B. J., McGechie, D. B., Rogers, P. A., and Glancy, R. J. (1985a). Pyloric Campylobacter infection and gastroduodenal disease. Med. J. Aust. 142, 439-444.

McCallion, W. A., Murray, L. J., Bailie, A. G., Dalzell, A. M., O'Reilly, D. .P., and Bamford, K. B. (1996). Helicobacter pylori infection in children: relation with current household living conditions. Gut 39, 18-21. doi: 10.1136/gut.39.1.18

Mehmet, N., Refik, M., Harputluoglu, M., Ersoy, Y., Aydin, N. E., and Yildirim, B. (2004). Serum and gastric fluid levels of cytokines and nitrates in gastric diseases infected with Helicobacter pylori. New Microbiol. 27, 139-148.

Mei, J., Liu, Y., Dai, N., Hoffmann, C., Hudock, K. M., Zhang, P., et al. (2012). Cxcr2 and Cxcl5 regulate the IL-17/G-CSF axis and neutrophil homeostasis in mice. J. Clin. Invest. 122, 974-986. doi: 10.1172/JCI60588

Morris, A., and Nicholson, G. (1987). Ingestion of Campylobacter pyloridis causes gastritis and raised fasting gastric $\mathrm{pH}$. Am. J. Gastroenterol. 82, 192-199.

Mózes, T., Baráth, I., Gornicsar, K., Grosz, A., Mózes, T., Göndöcs, P., et al. (2011). Madarász Deviations in circulating TNF $\alpha$ levels and TNF $\alpha$ production by mononuclear cells in healthy human populations. Mediators Inflamm. 2011:972609. doi: 10.1155/2011/972609

Nagashima, H., Iwatani, S., Cruz, M., Jiménez Abreu, J. A., Tronilo, L., Rodríguez, E., et al. (2015). Differences in interleukin 8 expression in Helicobacter pylori-infected gastric mucosa tissues from patients in Bhutan and the Dominican Republic. Hum. Pathol. 46, 129-136. doi: 10.1016/j.humpath.2014. 10.006

Noach, L. A., Rolf, T. M., and Tytgat, G. N. (1994). Electron microscopic study of association between Helicobacter pylori and gastric and duodenal mucosa. J. Clin. Pathol. 47, 699-704.

Numasaki, M., Watanabe, M., Suzuki, T., Takahashi, H., Nakamura, A., McAllister, F., et al. (2005). IL-17 enhances the net angiogenic activity and in vivo growth of human non-small cell lung cancer in SCID mice through promoting CXCR-2-dependent angiogenesis. J. Immunol. 175, 6177-6189. doi: 10.4049/jimmunol.175.9.6177

Papini, E., de Bernard, M., Milia, E., Bugnoli, M., Zerial, M., Rappuoli, R., et al. (1994). Cellular vacuoles induced by Helicobacter pylori originate from late endosomal compartments. Proc. Natl. Acad. Sci. U.S.A. 91, 9720-9724. doi: $10.1073 /$ pnas. 91.21 .9720
Park, S. M., Kim, J. H., Hong, Y. H., Jung, H. R., Park, J., Kim, J. G., et al. (2001). Expression of mucosal cyto-chemokine mRNAs in patients with Helicobacter pylori infection. Korean J. Intern. Med. 16, 230-235. doi: 10.3904/kjim.2001.16.4.230

Peek, R. M. Jr., Miller, G. G., Tham, K. T., Perez-Perez, G. I., Zhao, X., Atherton, J. C., et al. (1995). Heightened inflammatory response and cytokine expression in vivo to cagA+ Helicobacter pylori strains. Lab. Invest. 73, 760-770.

Peek, R. M. Jr., Fiske, C., and Wilson, K. T. (2010). Role of innate immunity in Helicobacter pylori-induced gastric malignancy. Physiol. Rev. 90, 831-858. doi: 10.1152/physrev.00039.2009

Pellicanò, A., Sebkova, L., Monteleone, G., Guarnieri, G., Imeneo, M., Pallone, F., et al. (2007). Interleukin-12 drives the Th1 signaling pathway in Helicobacter pyloriinfected human gastric mucosa. Infect. Immun. 75, 1738-1744. doi: 10.1128/IAI.01446-06

Rossi, G., Fortuna, D., Pancotto, L., Renzoni, G., Taccini, E., Ghiara, P., et al. (2000). Immunohistochemical study of lymphocyte populations infiltrating the gastric mucosa of beagle dogs experimentally infected with Helicobacter pylori. Infect. Immun. 68, 4769-4772. doi: 10.1128/IAI.68.8.4769-4772.2000

Ruddy, M. J., Shen, F., Smith, J. B., Sharma, A., and Gaffen, S. L. (2004). Interleukin-17 regulates expression of the CXC chemokine LIX/CXCL5 in osteoblasts: implications for inflammation and neutrophil recruitment. $J$. Leukoc. Biol. 76, 135-144. doi: 10.1189/jlb.0204065

Samson, C. M., Jurickova, I., Molden, E., Schreiner, W., Colliver, J., Bonkowski, E., et al. (2011). Denson Granulocyte-macrophage colony stimulating factor blockade promotes ccr9(+) lymphocyte expansion in Nod2 deficient mice. Inflamm. Bowel. Dis. 17, 2443-2455. doi: 10.1002/ibd. 21672

Satin, B., Del Giudice, G., Della Bianca, V., Dusi, S., Laudanna, C., Tonello, F., et al. (2000). The neutrophil-activating protein (HP-NAP) of Helicobacter pylori is a protective antigen and a major virulence factor. J. Exp. Med. 191, 1467-1476. doi: 10.1084/jem.191.9.1467

Sepulveda, A. R., and Patil, M. (2008). Practical approach to the pathologic diagnosis of gastritis. Arch. Pathol. Lab. Med. 132, 1586-1593. doi: 10.1043/1543-2165(2008)132[1586:PATTPD]2.0.CO;2

Sipponen, P., Kosunen, T. U., Samloff, I. M., Heinonen, O. P., and Siurala, M. (1996). Rate of Helicobacter pylori acquisition among Finnish adults: a fifteen year follow-up. Scand. J. Gastroenterol. 31, 229-232.

Smoot, D. T., Resau, J. H., Earlington, M. H., Simpson, M., and Cover, T. L. (1996). Effects of Helicobacter pylori vacuolating cytotoxin on primary cultures of human gastric epithelial cells. Gut 39, 795-799.

Smythies, L. E., Waites, K. B., Lindsey, J. R., Harris, P. R., Ghiara, P., and Smith, P. D. (2000). Helicobacter pylori-induced mucosal inflammation is Th1 mediated and exacerbated in IL-4, but not IFN-gamma, gene-deficient mice. J. Immunol. 165, 1022-1029. doi: 10.4049/jimmunol.165.2.1022

Suerbaum, S., and Michetti, P. (2002). Helicobacter pylori infection. N.Engl. J. Med. 347, 1175-1186. doi: 10.1056/NEJMra020542

Taub, D. D., Longo, D. L., and Murphy, W. J. (1996). Human interferoninducible protein-10 induces mononuclear cell infiltration in mice and promotes the migration of human $\mathrm{T}$ lymphocytes into In review the peripheral tissues and human peripheral blood lymphocytes-SCID mice. Blood 87, 1423-1431.

Telford, L. J., Ghiara, P., Dell’Orco, M., Comanducci, M., Burroni, D., Bugnoli, M., et al. (1994). Gene structure of the Helicobacter pylori cytotoxin and evidence of its key role in gastric disease. J. Exp. Med. 179, 1653-1658.

Territo, M. C., Ganz, T., Selsted, M. E., and Lehrer, R. (1989). Monocytechemotactic activity of defensins from human neutrophils. J. Clin. Invest. 84, 2017-2020.

Tkachenko, M. A., Zhannat, N. Z., Erman, L. V., Blashenkova, E. L., Isachenko, S. V., Isachenko, O. B., et al. (2007). Dramatic changes in the prevalence of Helicobacter pylori infection during childhood: a 10year follow-up study in Russia. J. Pediatr. Gastroenterol. Nutr. 45, 428-432. doi: 10.1097/MPG.0b013e318064589f

Tummuru, M. K., Sharma, S. A., and Blaser, M. J. (1995). Helicobacter pylori picB, a homologue of the Bordetella pertussis toxin secretion protein, is required for induction of IL-8 in gastric epithelial cells. Mol. Microbiol. 18, 867-876.

Tytgat, G. N. (1991). The Sydney System: endoscopic division. Endoscopic appearances in gastritis/duodenitis. J. Gastroenterol. Hepatol. 6, 223-234. 
Wuyts, A., Struyf, S., Gijsbers, K., Schutyser, E., Put, W., Conings, R., et al. (2003). The CXC chemokine GCP-2/CXCL6 is predominantly induced in mesenchymal cells by interleukin-1beta and is down-regulated by interferongamma: comparison with interleukin-8/CXCL8. Lab. Invest. 83, 23-34. doi: 10.1097/01.LAB.0000048719.53282.00

Xu, X. Q., Wang, Z. H., Liao, J. X., Chen, X. Y., Liu, W. Z., Xiao, S. D., et al. (2012). Predictive value of neutrophil infiltration as a marker of Helicobacter pylori infection. World J. Gastroenterol. 18, 5101-515. doi: 10.3748/wjg.v18. i36.5101

Yamada, S., Kato, S., Matsuhisa, T., Makonkawkeyoon, L., Yoshida, M., Chakrabandhu, T., et al. (2013). Predominant mucosal IL-8 mRNA expression in non-cagA Thais is risk for gastric cancer. World J. Gastroenterol. 19, 2941-2949. doi: 10.3748/wjg.v19.i19.2941

Yamaoka, Y., Kita, M., Kodama, T., Sawai, N., and Imanishi, J. (1996). Helicobacter pylori cagA gene and expression of cytokine messenger RNA in gastric mucosa. Gastroenterology 110, 1744-1752.
Yamaoka, Y., Kita, M., Kodama, T., Sawai, N., Tanahashi, T., Kashima, K., et al. (1998). Chemokines in the gastric mucosa in Helicobacter pylori infection. Gut $42,609-617$.

Conflict of Interest Statement: The authors declare that the research was conducted in the absence of any commercial or financial relationships that could be construed as a potential conflict of interest.

Copyright (c) 2016 Khaiboullina, Abdulkhakov, Khalikova, Safina, Martynova, Davidyuk, Khuzin, Faizullina, Lombardi, Cherepnev and Rizvanov. This is an openaccess article distributed under the terms of the Creative Commons Attribution License (CC BY). The use, distribution or reproduction in other forums is permitted, provided the original author(s) or licensor are credited and that the original publication in this journal is cited, in accordance with accepted academic practice. No use, distribution or reproduction is permitted which does not comply with these terms. 